\title{
Simulation of fatigue small crack growth in additive manufactured Ti-6Al-4V material
}

Received: 29 January 2020 / Accepted: 10 March 2020 / Published online: 25 March 2020

(C) The Author(s) 2020

\begin{abstract}
Additive manufacturing (AM) offers design freedom and ability to fabricate parts of complex shapes which are not often possible with the conventional methods of manufacturing. In an AM part, even with optimum build parameters, a complete elimination of defects is not possible and this makes it hard to fully deploy the AM technology to build load bearing parts operating under cyclic loading conditions. Many of these defects are $<$ $1 \mathrm{~mm}$ in size and are categorised as 'small cracks'. Local interaction of cracks with microstructural features and closure effects at the wake of the crack tip are some of the factors which make the growth behaviour of small and long cracks different. A crack growth life prediction method, which effectively considers the small crack growth behaviour, has been discussed in this paper. This proposed method includes a detailed finite elementbased crack growth simulation using the ANSYS SMART fracture technology. The lifing calculations utilise the modified NASGRO equation and small crack growth data which was obtained from the published long crack growth data, corrected for closure effects. The predicted stress versus number of cycles curves were compared against the fatigue test results for the AM specimens in Ti-6Al-4V material. A good correlation between the predictions and test results suggests that the proposed method can be used to assess the small crack growth life of AM parts where the fatigue effects of cyclic loading can be quite significant.
\end{abstract}

Keywords Selective laser melting $\cdot$ Fatigue $\cdot$ Physically small cracks $\cdot$ Crack growth $\cdot$ Defects $\cdot$ Ti-6Al-4V

\section{Introduction}

In comparison with subtractive manufacturing methodologies, the additive manufacturing (AM) is defined as 'a process of joining materials to make objects from 3D model data, usually layer upon layer' [1]. The laser powder bed fusion (LPBF) process, also known as selected laser melting (SLM), is a popular AM technique, which involves depositing a thin layer of powder onto a build plate and melting the powder in a predefined pattern using a laser beam to build a part track after track and layer upon layer [2,3]. AM methods of manufacture have many advantages over conventional methods, offering high material usage efficiency, since near-net (or actual)-shape parts are produced by the process and the material powder can be reused [3-6]. It also offers the ability to fabricate parts with complex shapes which are not often possible with conventional methods of manufacturing $[2,3,7,8]$. A lower part count saves time during assembly, helps to reduce the inventory

Communicated by Andreas Öchsner.

A. Gupta $(\varangle)$

Rolls Royce plc, Derby DE24 8BJ, UK

E-mail: alok.gupta@rolls-royce.com

A. Gupta · W. Sun · C. J. Bennett

Faculty of Engineering, Gas Turbine and Transmissions Research Centre (G2TRC), University of Nottingham, University Park, NG NG7 2RD, UK 
cost and makes the supply chain easier to manage. Onsite fabrication of replacement parts, manufacturing of tailored/bespoke parts and efficient production of parts are amongst the other advantages due to which AM methods are rapidly gaining popularity in the aerospace, automobile and biomedical sectors $[9,10]$.

In an AM part, the defects (voids and pores) can form as the shielding gas is trapped in the melt pool during the deposition process. The majority of these voids and pores are spherical but can sometimes be of irregular shape due to multiple pockets of gas coalescing or areas experiencing a lack of fusion $[2,4,5,10-13]$. The size of the pores and voids, their physical location (i.e. surface vs internal) and the fatigue life are linked $[2,14]$. For material under fatigue loading, the crack initiation and propagation between the surface and internal defects remain competitive depending upon their size and stress levels $[14,15]$. Typically, surface cracks occur at high stress levels and the associated fatigue life is relatively short because of the environmental effects $[14,15]$. The crack initiations from interior defects generally lead to long life because of crack growth in a quasi-vacuum environment $[14,15]$; however, interior crack initiation not associated with any internal defects can also occur in titanium alloys, meaning that the crack initiation can shift from surface to interior (sub-surface) [14]. Since a complete elimination of defects is not possible in any AM process, care should be exercised to develop the optimum build parameters for an AM process and use them to build parts with reduced size of voids and pores $[11,16]$.

Ti-6Al-4V is the most commonly used titanium alloy in aerospace industry due to its high strengthto-weight ratio, excellent corrosion resistance, toughness, good ductility and adequate fracture toughness $[15,17-19]$. The Ti-6Al-4V alloy produced from the AM processes has shown good tensile, fatigue and fracture properties [17], and it also offers the possibility to choose from a variety of microstructures, e.g. lamellar $\alpha$, colony $\alpha$ or martensitic $\alpha^{\prime}$ within $\beta$ matrix [18]. The study of fatigue crack growth has received considerable interest for Ti-6Al-4V AM parts [16,20]; however, understanding and prediction of fatigue crack growth behaviour in the presence of inherent surface and internal defects still remain a challenge [19].

For parts made of conventional methods of manufacturing, several theoretical methods of predicting fatigue and crack growth have been applied with confidence. But this is not true for AM parts where the fatigue and fracture studies of AM parts until now are mostly experimentally based and theoretical studies are relatively limited [21]. In a theoretical study by Zhan et al. [21], a continuum damage mechanics (CDM)-based method has been proposed to predict the fatigue life of AM parts. In the proposed method, a concept of relative volumetric energy density was introduced which takes into account the laser power, scan speed, hatch spacing and powder layer thickness. Although the material parameters were calibrated using the experimental results, this approach still has shortfalls in the sense that it does not address the effect of specific variations in material microstructure and anisotropic behaviour associated with build direction. In another study by Jones et al. [16], it is suggested that the Hartman-Schijve variant of NASGRO crack growth equation can be utilised to predict the crack growth of AM parts irrespective of specific AM process, power levels and build direction. The calculated crack growth rate $(\mathrm{d} a / \mathrm{d} N)$ versus stress intensity range $(\Delta K)$ curves showed a reasonably good match against the experimentally obtained crack growth curves from various studies. In their calculations, Jones et al. [16] adjusted the values of effective lower fatigue threshold and cyclic fracture toughness parameters to achieve a good fit against the experimental data. The physical meaning of effective lower fatigue threshold is not clear, and the values of both these parameters could be different from those obtained from the experiments. Moreover, in both the studies $[16,21]$ the effect of size, shape and distribution of defects in AM parts have not explicitly been discussed, and therefore, the use of these two theoretical methods for practical applications is judged to be limited.

From a recently publication, Fomin et al. [22] in their research have proposed a fatigue life assessment model which considers the effects of small cracks for laser-welded Ti-6Al-4V butt joints in HCF regime. Their proposed small crack growth model considered the 'cyclic R-curve' as a mean to reflect the reduced threshold value and the crack length dependent $\Delta K_{\text {th }}(a)$ for small cracks. They suggested that by using the 'cyclic R-curve', the small crack effects can be analysed by introducing the dependence $\Delta K_{\text {th }}(a)$ in the crack growth equation. The construction of 'cyclic R-curve' comes with challenges and, as suggested by Fomin et al. [22] in their simple approach to construct the 'cyclic R-curve' for internal cracks, it requires the knowledge of the intrinsic effective threshold stress intensity factor $\left(\left(\Delta K_{\text {eff }}\right)\right.$ th $)$ for small cracks, the fatigue endurance limit of the material and the threshold stress intensity for the long cracks $\left(\Delta K_{\mathrm{th}} \mathrm{LC}\right)$. Furthermore, to construct a 'cyclic R-curve' there are other approaches outlined by Zerbst et al. [23,24], which includes the experimentbased techniques and also the approaches utilising the Kitagawa-Takahashi diagram [25] and the Murakami' model of square root of the area of small surface cracks [26]. All these approaches to construct the 'cyclic R-curves' require extensive test and validation program for AM materials. Due to lack of sufficient test data to 
develop the 'cyclic R-curve' specific to AM Ti-6Al-4V material, it makes the adoption of 'cyclic R-curve'based approach in the small crack growth predictive tools and methods quite challenging.

A crack growth life prediction method for AM parts, which effectively considers the small crack growth behaviour, has been proposed in this paper. This method includes a detailed finite element (FE)-based crack growth simulation using the ANSYS separating morphing and adaptive re-meshing technology (SMART) fracture technology. The lifing calculations utilise the modified NASGRO equation and small crack growth data for AM Ti-6AL-4V material reported by Zhai et al. [27]. The predicted stress versus number of cycles curves are compared against the experimental fatigue test results reported by Gong et al. [20]. Three different test cases were studied and details of analysis together with results, discussion and conclusions, and some recommendations are presented in this paper.

\section{Small crack growth behaviour and modified NASGRO equation}

Cracks are categorised based on the relationship between their dimensions, as shown in Fig. 1, such as length $(a)$ and width $(w)$, length of shielding zone $\left(l_{\mathrm{s}}\right)$, characteristic microstructural size $\left(m_{\mathrm{s}}\right)$ and the plastic zone radius $\left(r_{\mathrm{p}}\right)[23,28-31]$. A physically small crack (hereafter referred as small crack) is defined as a crack of length in the range between $20 \mu \mathrm{m}$ and $1 \mathrm{~mm}$ [24] and is generally smaller than the typical non-destructive testing (NDT) detection limit $(<1 \mathrm{~mm})$ [29,32-34]. For long cracks, the concept of crack closure was introduced by Elber in 1970 [35]. Closure in the wake of a long crack reduces the effectiveness of the applied crack tip stress intensity, thus retards the crack growth process $[23,34,36]$. For long cracks, the effect of the plastic zone in the applicable ' $\mathrm{d} a / \mathrm{d} N$ versus $\Delta K$ ' curve is implicit in the stress intensity factor (SIF)-dominated stress field [23]. Researchers have studied the closure levels in the small and long crack regimes and suggested that the developing crack wake in small cracks is generally less well developed than in long cracks, and therefore, the overall plasticity induced crack closure effect is negligible in small crack growth rate $[16,27,29,35,37,38]$. As a result, the effective stress ranges for small cracks are greater than that for long cracks under the same applied (far-field, nominal) stress ranges and the crack growth rates of small cracks can be significantly greater than the corresponding rate of the long cracks when characterised in terms of the same driving force or $\Delta K$ levels $[27,29,34,35,37,38]$. The local interaction of cracks with microstructural features, chemical activity at the crack tip and the closure effects at the wake are some of the factors which make the growth behaviour of small and long cracks different, as depicted schematically in the $\mathrm{d} a / \mathrm{d} N$ versus $\Delta K$ shown in Fig. 2. Furthermore, in the analysis of small crack growth, the use of long fatigue crack data may lead to overestimates [16,29]. The analysis of small crack growth remains challenging and complex [27,29,31,34,39], and therefore, a more detailed understanding of small crack growth behaviour is required, particularly for components fabricated by one of the AM processes [16,27].

The life prediction method for small cracks proposed by Zhang et al. [40] avoids the complex crack growth analysis, and the fatigue life is calculated by directly integrating the crack growth model from the initial crack size $\left(a_{\mathrm{i}}\right)$ to the critical crack size $\left(a_{\mathrm{c}}\right)$. The method starts with the crack growth equation in the NASGRO code-

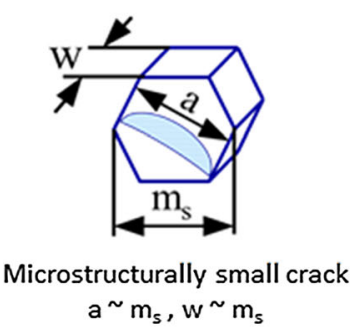

(a)

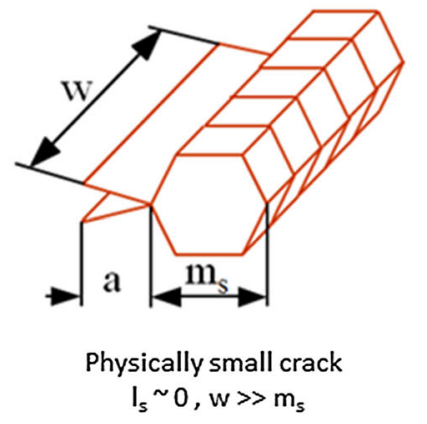

(b)

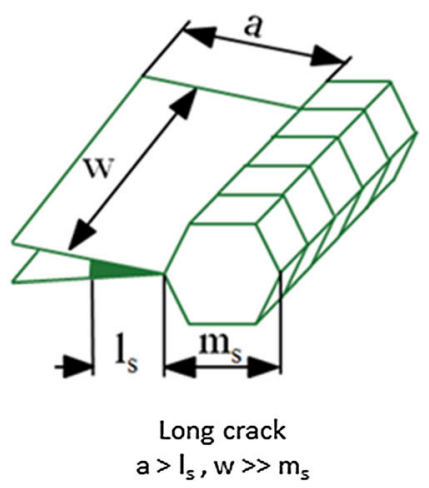

(c)

Fig. 1 Categorisation of a microstructurally small crack, b physically small crack and $\mathbf{c}$ long crack [27] 


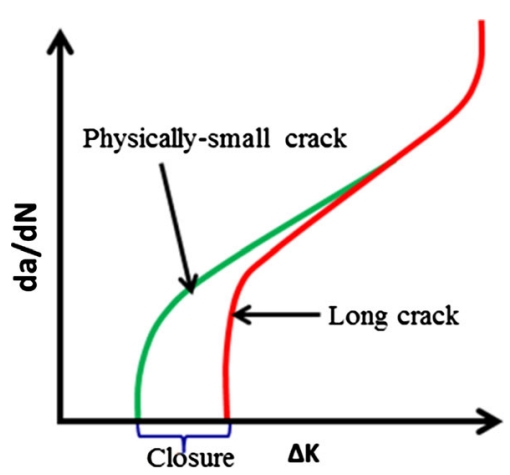

Fig. 2 Qualitative comparison of physically small and long crack growth behaviours [27]

$$
\frac{\mathrm{d} a}{\mathrm{~d} N}=C_{1}\left(\Delta K_{\mathrm{eff}}\right)^{C_{2}} \frac{\left(1-\Delta \frac{K_{\mathrm{th}}}{\Delta K}\right)^{p}}{\left(1-\frac{K_{\max }}{K_{\mathrm{c}}}\right)^{q}}
$$

where $\frac{\mathrm{d} a}{\mathrm{~d} N}$ is the fatigue crack growth rate, $\Delta K_{\text {th }}$ is the threshold SIF range, $\Delta K$ is the stress intensity range, $K_{\max }$ is the maximum SIF, $\Delta K_{\text {eff }}$ is the SIF range for small crack, $K_{\mathrm{c}}$ is the critical SIF and $C_{1}, C_{2}, p$ and $q$ are empirically determined materials constants. $K_{\text {eff }}$ can be written as a function of the $U$ factor, used to get the equivalent SIF range for small cracks from the SIF range for long cracks, and $\Delta K$ :

$$
\Delta K_{\text {eff }}=U \Delta K
$$

Also Zhang et al. [40] considered the crack closure effect and introduced the concept of 'Intrinsic effective threshold stress intensity factor' $\left(\Delta K_{\text {eff }}\right)_{\text {th }}$ and treated this as a material property, independent of the stress ratios or experimental techniques. Therefore, the NASGRO equation was modified as below;

$$
\frac{\mathrm{d} a}{\mathrm{~d} N}=C_{1}\left(\Delta K_{\mathrm{eff}}\right)^{C_{2}} \frac{\left(1-\frac{\left(\Delta K_{\text {eff }}\right)_{\mathrm{th}}}{\Delta K_{\text {eff }}}\right)^{p}}{\left(1-\frac{K_{\max }}{K_{\mathrm{c}}}\right)^{q}}
$$

Since during the fast crack propagation stage, only a very small part of the fatigue life is consumed, Eq. 3 can be simplified to:

$$
\frac{\mathrm{d} a}{\mathrm{~d} N}=C_{1}\left(\Delta K_{\mathrm{eff}}\right)^{C_{2}}\left(1-\frac{\left(\Delta K_{\mathrm{eff}}\right)_{\mathrm{th}}}{\Delta K_{\mathrm{eff}}}\right)^{p}
$$

And then, the fatigue life can be calculated as:

$$
N=\int_{a_{1}}^{a_{c}} \frac{1}{C_{1}\left(\Delta K_{\text {eff }}\right)^{C_{2}}\left(1-\frac{\left(\Delta K_{\text {eff }}\right)_{\mathrm{th}}}{\Delta K_{\text {eff }}}\right)^{p}} \mathrm{~d} a
$$

where, the value of $p$ is typically assumed to take a value of $2[16,41] . \Delta K_{\text {eff }}$ is the stress intensity range for small cracks, and $\left(\Delta K_{\text {eff }}\right)_{\text {th }}$ is the threshold stress intensity range for small cracks.

\section{FE-based crack growth simulation and lifing calculation}

The crack growth assessment of an AM part with inherent defects can be carried out using a finite element (FE)based simulation approach. The previously existing FE simulation approaches for crack growth were found to be quite complicated and required manual meshing and re-meshing to calculate crack growth. Engineers had to continuously tweak the mesh involving 'hexahedron' and 'wedge' elements to capture the crack front; thus, a simulation consumed a great amount of time (up to several days). Furthermore, an ideal mesh using only hexahedron (hereafter referred as Hex) elements was often not possible and required simplification of the geometry of the crack to fit a Hex-only mesh pattern, resulting in loss of fidelity in the crack growth analysis [42]. 

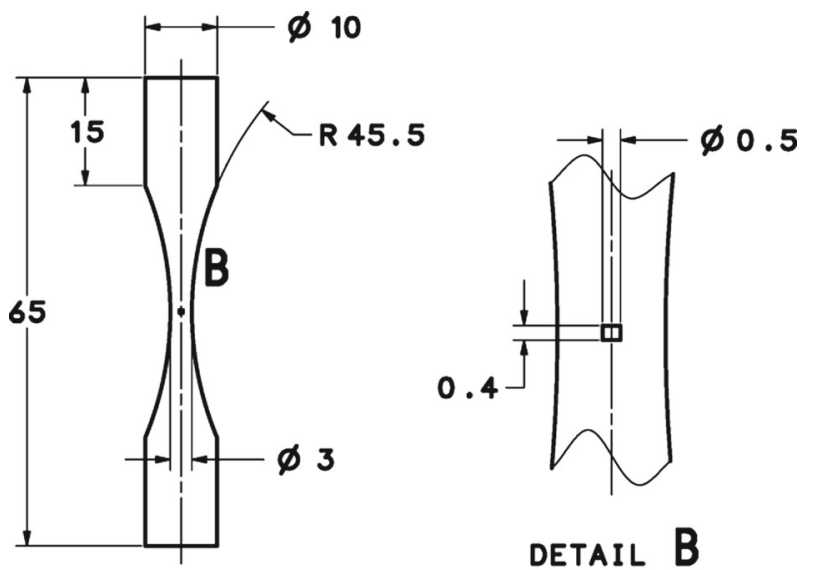

Fig. 3 Fatigue specimen dimensions ( $\mathrm{mm}$ ) and designed cylindrical defect in the specimen in detail B [20]

The crack growth simulation in this study was carried out using the ANSYS SMART fracture technology which was recently integrated within the ANSYS package v19.1. The SMART simulation of crack propagation was based on Paris' law using all-tetrahedral (Tet) mesh for the crack fronts, where the mesh was updated automatically as the crack front changed due to crack growth. This achieves the same high-fidelity results as from a simulation with the ideal Hex mesh configuration, and the rate of crack growth and the number of cycles to failure under fatigue loading are predicted [42].

\subsection{Source of material, additive process and experimental data}

For the purpose of the current study, the test results reported by Gong et al. [20] were used. The material used to build the specimens was EOS Ti-6Al-4V, and the max impurity concentration of the powder was as per American Society for Testing and Materials-(ASTM) F1472 [43]. The particle size of the powder was normally distributed with a mean of $38 \mu \mathrm{m}$ and ranged from 25 to $53 \mu \mathrm{m}$ [20]. The test specimens were built with their longitudinal axis aligned vertically using the EOS M270 direct metal laser sintering system (DMLS). The processing parameters included laser power $170 \mathrm{~W}$, scan speed $1250 \mathrm{~mm} / \mathrm{s}$, hatch spacing $100 \mu \mathrm{m}$ and layer thickness $30 \mu \mathrm{m}$.

The test results for the following two types of specimens were considered in this study:

- Type 1: No internal designed defect,

- Type 2: With internal designed defect of cylindrical shape

The CAD file for specimen with an internal designed defect contained an internal void of cylindrical shape, as shown in Fig. 3 [20].

For the purpose of this study, the following three analysis cases were studied (Fig. 4):

Case A: No internal designed defect: crack initiating at the surface

Case B: With internal designed defect of cylindrical shape: crack initiating at the surface

Case C: With internal designed defect of cylindrical shape: crack initiating at the cylindrical defect

Both Type 1 and Type 2 specimens were stress relieved using heat treatment at $650^{\circ} \mathrm{C}$ for $4 \mathrm{~h}$ in an argon environment followed by the furnace cooling to room temperature. Light sand blasting was used to remove the adhered powder particles from the surface of the specimens. The fatigue tests were carried out using the sinusoidal load at R-ratio of 0.1 , with a frequency of $50 \mathrm{~Hz}$ and at different stress levels [20].

\subsection{Small crack growth data}

Crack closure is a major mechanism at the near threshold part of the crack growth curve $[16,29,31,34]$; therefore, reliable closure free crack growth data is needed to accurately predict small crack growth [36]. 


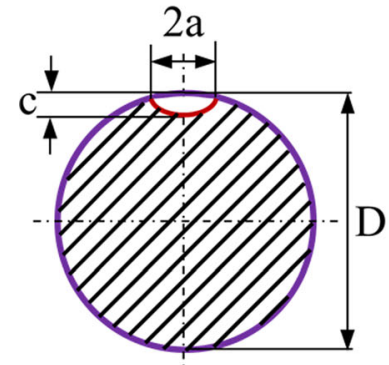

(a)

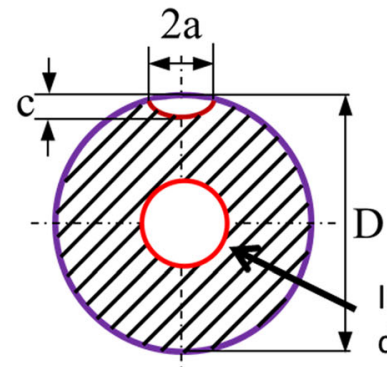

(b)

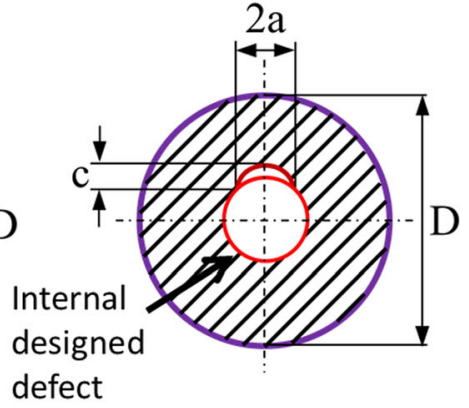

(c)

$D=$ Diameter of the specimen, $c=$ depth of crack, $2 a=$ length of crack

Fig. 4 ANSYS SMART crack analysis: a analysis Case A, b analysis Case B and $\mathbf{c}$ analysis Case C, an illustration (not to scale)

Table 1 Long and small fatigue crack growth data (@low power + heat treatment)_LPHT-V [27]

\begin{tabular}{lll}
\hline Parameters & Long fatigue crack growth data & Small fatigue crack growth data \\
\hline$\Delta K_{\text {th }}(\mathrm{MPa} \sqrt{ } \mathrm{m})$ & 2.9 & 2.4 \\
$\Delta K_{\mathrm{FT}}(\mathrm{MPa} \sqrt{ } \mathrm{m})$ & 46.7 & - \\
$C_{1}\left(\mathrm{~m} /\left(\operatorname{cycle} \times(\mathrm{MPa}) \sqrt{ } \mathrm{m}^{C_{2}}\right)\right)$ & $1.4 \times 10^{-12}$ & $2.6 \times 10^{-12}$ \\
$C_{2}$ & 4.0 & 3.9 \\
\hline
\end{tabular}

ASTM E647-15 [44] introduced the adjusted compliance ratio (ACR) method to determine the closure free $\mathrm{da} / \mathrm{dN}$ versus $\Delta K$ relationship [27,41], and Donald et al. [36] provided the detailed steps to determine ACR. Furthermore, the fatigue crack propagation threshold, $\Delta K_{\text {th }}$, is a crucial parameter in the framework of a damage tolerant analysis and design [23,34,39]. As illustrated in Fig. 2, small fatigue cracks grow at a stress intensity factor (SIF) range below the long crack fatigue threshold [27,29,30,34,37,38] and the fatigue crack propagation threshold $\left(\Delta K_{\text {th }}\right)$ associated with small cracks is less than that for long cracks $[16,29]$.

Small fatigue crack growth data, corrected for crack closure effects from long crack growth data, for Ti6AL-4V AM material specimens, manufactured using laser engineering net shaping (LENS) from the work of Zhai et al. [27] were used in this work. While there are possible differences between LENS and DMLS $\mathrm{AM}$, both processes use a laser heat source and a similar build environment and, therefore, the assumption is made that the specimens are likely to have similar microstructure and defect distributions for the purpose of this work.

The test specimens from Zhai et al. [27] were built using the low- and high-power levels, and both as-built and heat-treated specimens were tested. The long fatigue crack growth data from the low power heat-treated vertical (LPHT-V) propagation specimen was used in the SMART crack growth analysis. The use of LPHT-H data were ruled out due to weakening effects of lack of fusion and irregular-shaped defects which are highly possible at low power and low energy density [4,12,13]. Zhai et al. [27] also provided the fatigue crack growth data for small cracks, which were produced after applying the adjusted compliance ratio (ACR) technique on the long fatigue crack growth data [36].

In order to obtain the $U$ factor (Eq. 2), the Paris' parameters and threshold stress intensity values ( $\left.\Delta K_{\text {th }}\right)$ for long and small crack growth rates, presented in Table 1, were used to first determine the idealised $\mathrm{d} a / \mathrm{d} N$ versus $\Delta K$ crack growth curves for small and long cracks, as shown in Fig. 5a, and then, the $U$ versus $\Delta K$ curve was calculated using Eq. 2 for each value of $\Delta K$, Fig. 5b. In Eq. 2, $\Delta K_{\text {eff }}$ is the maximum SIF range for a small crack.

\subsection{FE-based crack growth simulation}

Crack growth simulations were carried out using the geometry of fatigue specimens shown in Fig. 3. To reduce the overall size of the FE model, to improve computational efficiency, only the uniform cylindrical section was used for the simulation and two different types of defect geometry were considered. 


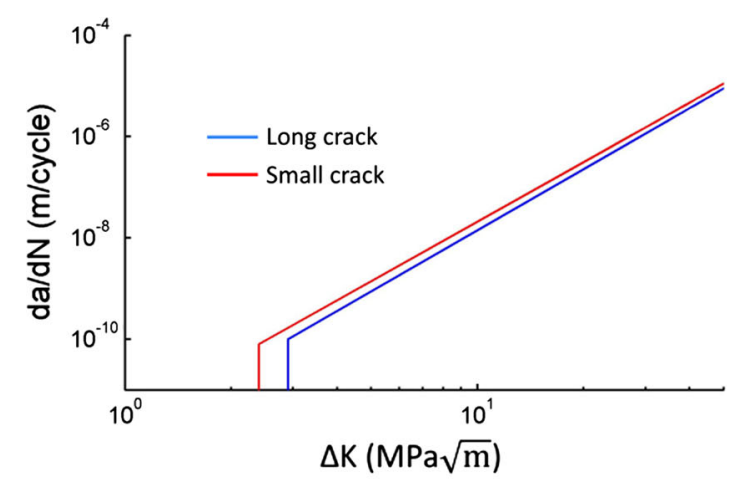

(a)

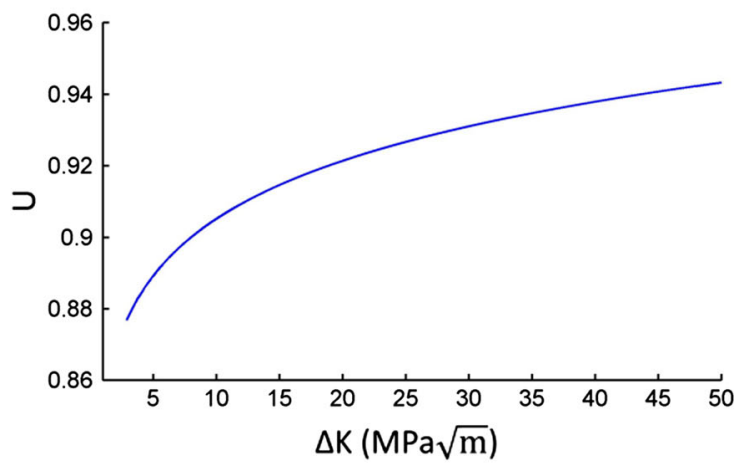

(b)

Fig. 5 a Idealised long and small and fatigue crack growth curves, b $U$ versus $\Delta K$ curve

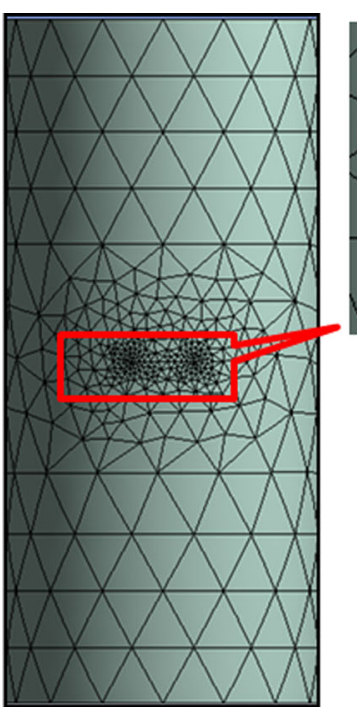

(a)

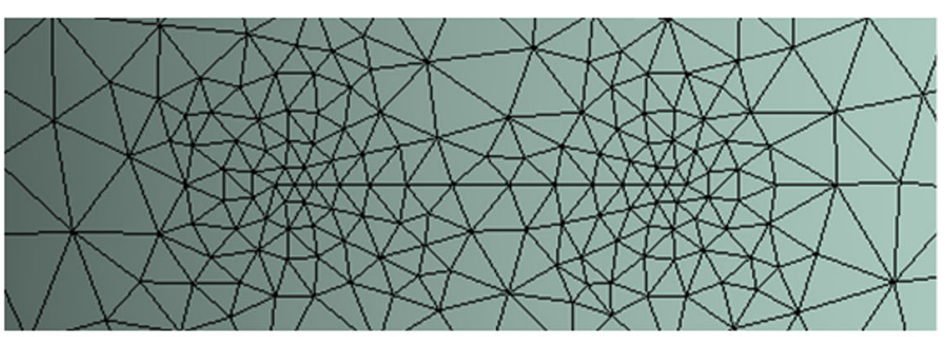

(b)

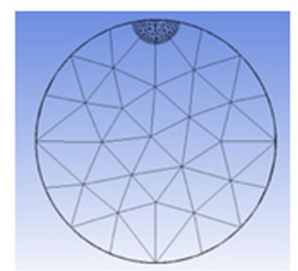

(c)

Fig. 6 Finite element mesh and inserted surface crack (Case A): a FE mesh and inserted surface crack, b front view, $\mathbf{c}$ top view

Type 1: With no internal designed defect (for analysis Case A) and

Type 2: With internally designed defect of cylindrical shape (for analysis Cases B and C).

The Young's modulus and Poison's ratio for Ti-6Al-4V were taken as $110 \mathrm{GPa}$ and 0.3, respectively [45].

The FE mesh was generated using the 'Tet' elements on the cylindrical sub-scale model. Within the ANSYS SMART fracture tool, a semi-elliptical crack of the desired size was inserted on the surface [for analysis Cases A (Fig. 4a) and B (Fig. 4b)] or on the surface of the cylindrical defect [for analysis Case C (Fig. 4c)]. A typical body-controlled coarse mesh size of $\sim 0.5 \mathrm{~mm}$ was assigned to the main body of the sub-scale model. The mesh was refined at the inserted crack front, which is typically five times finer than the mesh in the main body of the specimen. The mesh sensitivity study has shown that such a mesh size ensures contour independence of calculated J-integral. The mesh contour number for J-integral calculation is set to 5 for all simulations. This is very important to avoid analysis errors and to obtain accurate fracture predictions. A typical mesh is shown in Fig. 6.

The ANSYS SMART crack growth analyses were run at a load ratio (R) of 0.1 , in accordance with the experimental testing [20], with one end of the specimen assumed as fixed and the cyclic load applied at the other end, Fig. 7. Analyses were run with different initial crack sizes and under different load levels for each of the analysis cases studied. Even though the initial crack size assumed was the size of a small crack, the simulation was run using the linear elastic fracture mechanics (LEFM) approach using the crack growth parameters for long crack. 


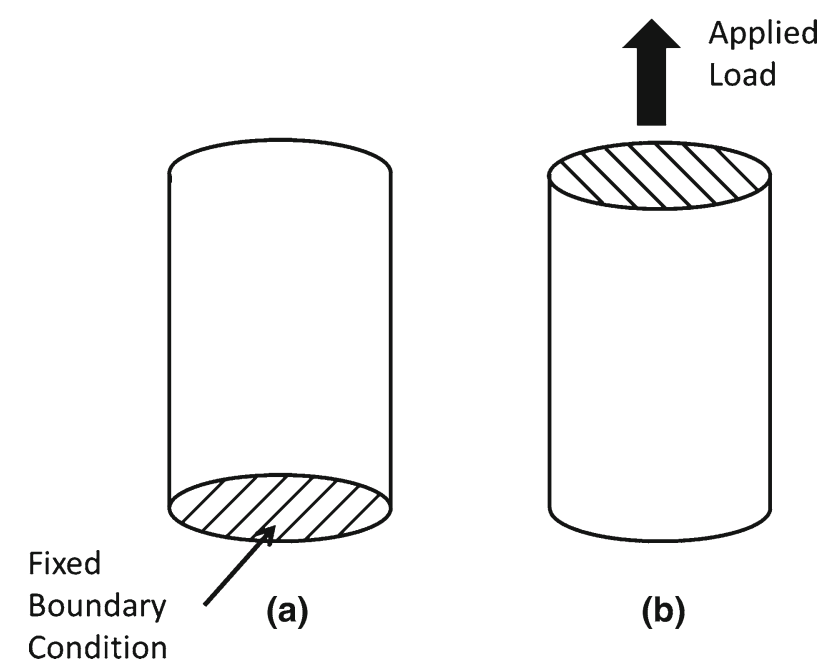

Fig. 7 SMART crack growth analysis, boundary condition and loading application: a fixed boundary condition and $\mathbf{b}$ applied load

Table 2 Initial defect sizes assumed for three analysis cases

\begin{tabular}{ll}
\hline Analysis case & Initial defect sizes- $2 a(\mathrm{~mm})$ \\
\hline Case A & $0.046,0.07,0.1,0.17$ \\
Case B & $0.1,0.17$ \\
Case C & $0.04,0.06$
\end{tabular}

For the three cases studied, the SMART crack growth analyses were run for different initial defect sizes (2a) as shown in Table 2. This was due to the fact that defect size could vary from specimen to specimen. For each of the initial crack sizes, the SMART crack growth analyses were run for multiple sub-steps until fracture.

From the SMART crack growth analysis, the results of LEFM $\Delta K$ (stress intensity factor range) and $\mathrm{d} a$ (crack extension) against the time steps were extracted for different initial crack sizes and loads. Using these results, the corrected small crack growth live from AM specimens was then calculated.

\subsection{Small crack growth lifing calculation}

An overview of the methodology for the lifing calculation is presented in Fig. 8.

The steps followed to calculate the total life from a small crack to fracture can be summarised as follows:

i. Run the LEFM analysis using the SMART simulation using the fatigue crack growth data for long crack and for different crack sizes and cyclic load values chosen for the SMART crack growth analysis.

ii. The idealised crack propagation rates for long and small cracks were generated using the fracture data in Table 1. These Idealised crack growth curves are shown in Fig. 5a.

iii. The $U$ factor was obtained against increasing values of $\Delta \mathrm{K}$ using the idealised crack growth curves for long and small cracks (see Fig. 5a) and using the equation below

$$
U=\frac{\Delta K_{\mathrm{eff}}}{\Delta K}
$$

where $\Delta K$ and $\Delta K_{\text {eff }}$ are the stress intensity factor range for long crack and small cracks, respectively. The $U$ versus $\Delta K$ curve was obtained as shown in Fig. 5b. A polynomial regression line and associated fitting parameters were obtained for the subsequent life cycle calculations.

iv. For each time step, using the predicted stress intensity range $(\Delta K)$ and crack extension values $(\mathrm{d} a)$ from the SMART simulation (from Step i), the crack growth data presented in Table 1 and $U$ factors (from step iii) as input to Eq. 5, the total number of cycles to fast fracture were calculated. 


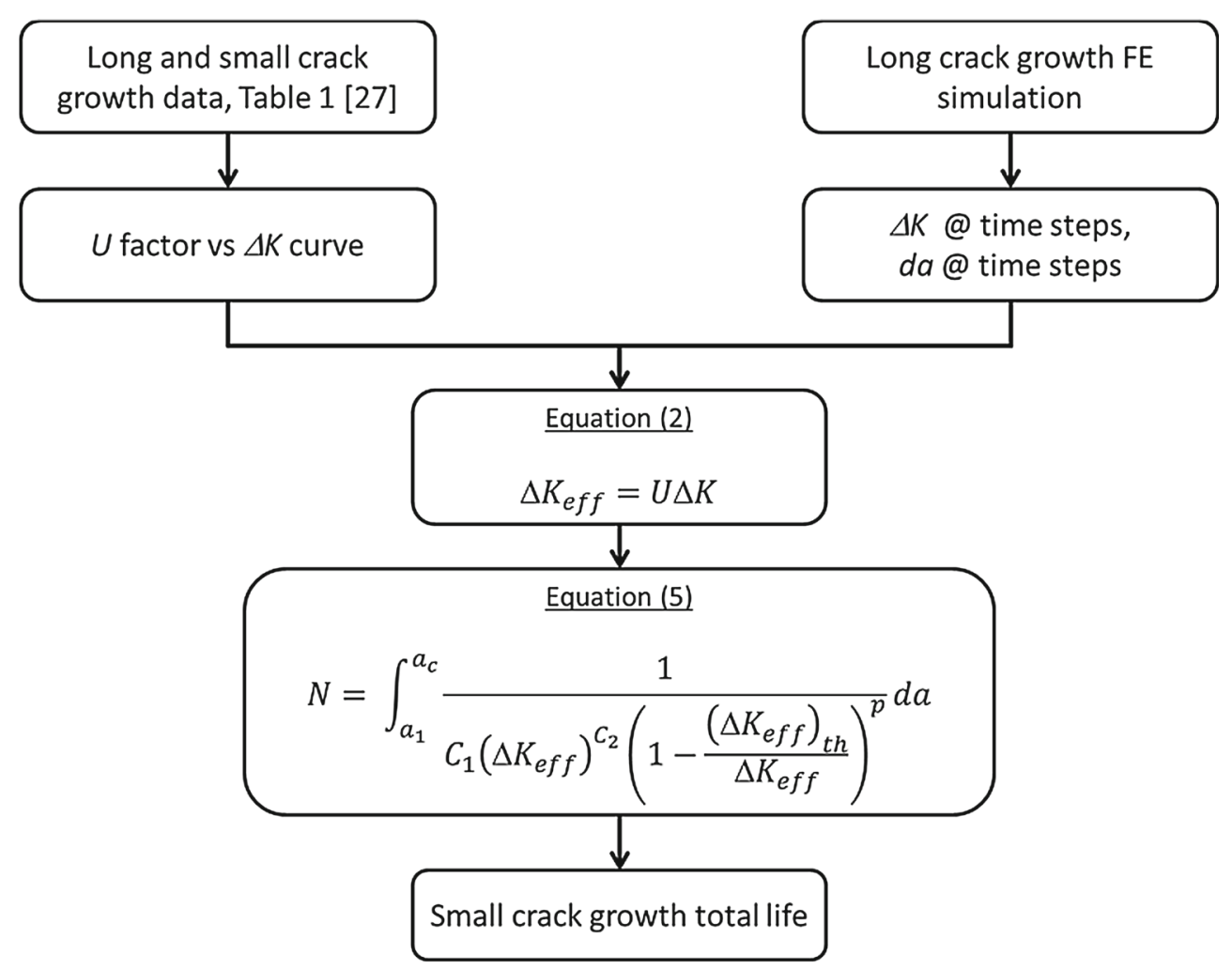

Fig. 8 Small crack lifing calculation steps

v. Analysis calculations were repeated for different initial crack sizes and different applied load values and graphs of stress versus number of cycles were plotted for each of the analysis cases.

\section{Results and discussion}

The predicted analysis results (i.e. stress versus number of cycles) for each of the analysis cases were compared against the fatigue test data presented by Gong et al. [20].

\subsection{Case A: No internal designed defect crack initiating at the surface}

As shown in Table 2, for Case A, the SMART crack growth analyses were run for the initial defect sizes $(2 a)$ of $0.046 \mathrm{~mm}, 0.07 \mathrm{~mm}, 0.1 \mathrm{~mm}$ and $0.170 \mathrm{~mm}$. From the analysis with $0.1 \mathrm{~mm}$ initial crack size, the plots of maximum stress intensity at sub-steps 1, 10 and 25 are illustrated in Fig. 9, which illustrates a propagating crack and corresponding change in maximum stress intensity.

Figure 10 shows predicted crack sizes for sub-steps 1, 10 and 25. During the simulation, auto-refinement of the mesh around and at the crack front takes place at each incremental sub-step (Fig. 10). Figure 11 shows the deformation at the final sub-step of the crack growth and corresponding maximum stress intensity factor approaching the fracture toughness.

The predicted lifing curves for small crack growth calculations were compared against the fatigue test data of [20], Fig. 12. Though the predicted lifing curve for $0.1 \mathrm{~mm}$ initial defect size appears to be following the three failure points observed in experiments [20], it can be seen that all the experimentally observed failure points fall between the predicted curves for the initial defect of $0.1 \mathrm{~mm}$ and $0.170 \mathrm{~mm}$ in size.

The rough surface of the as-built gauge section is an ideal site for the stress raising features which adversely affect the fatigue life of the specimen [20]. Cracks usually initiate at one of the sites with the highest stress concentration from the surface and then propagate through the section before final fracture occurs. The frac- 


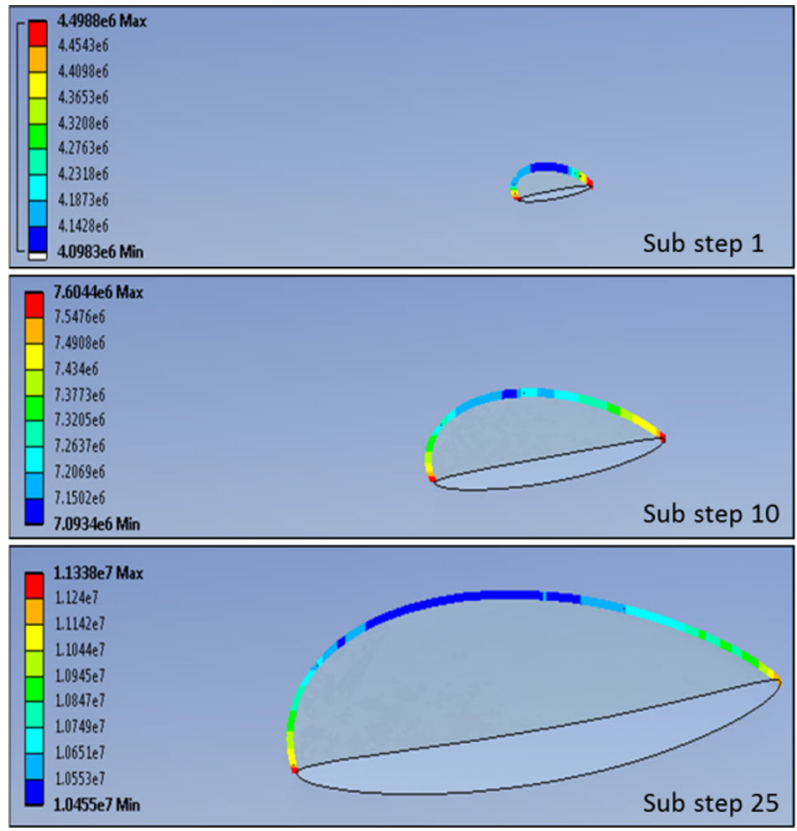

Fig. 9 Max stress intensity at different sub-steps
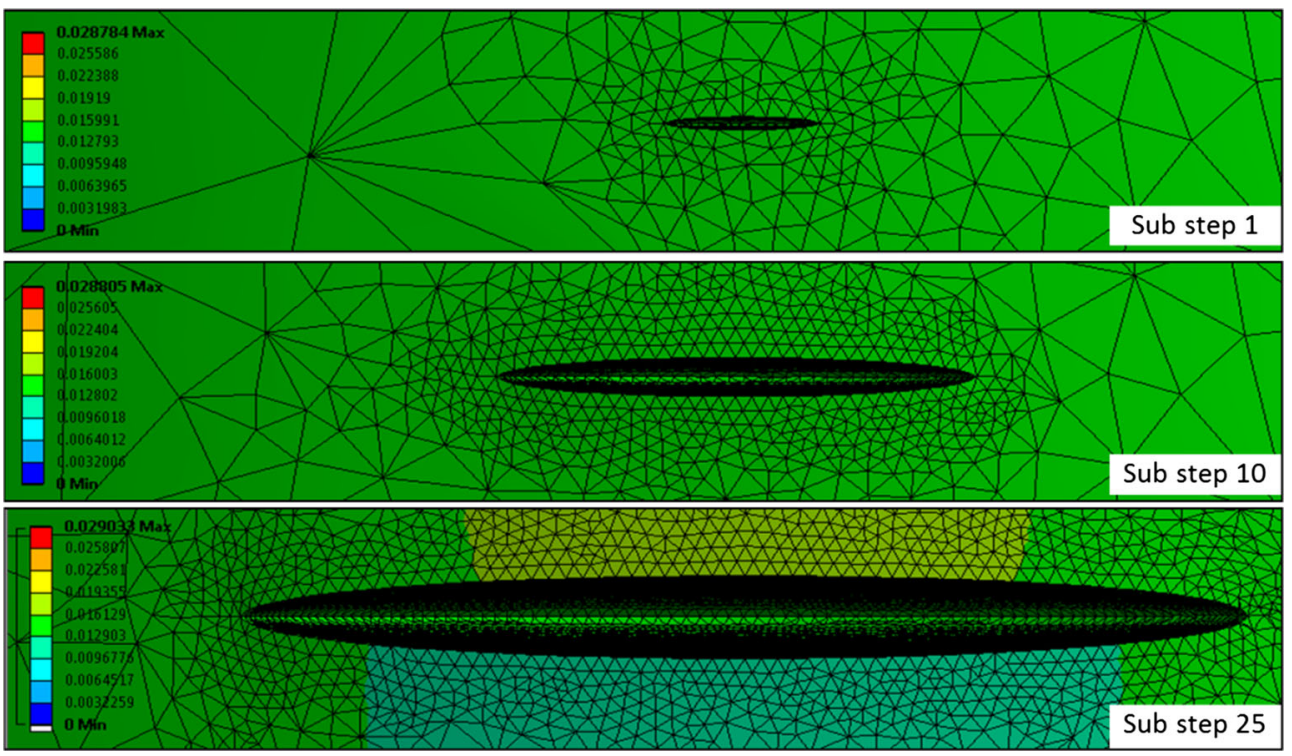

Fig. 10 Crack propagation and auto-mesh refinement around the propagating crack

tographic image from the experiments for Case A [20], Fig. 13, was reviewed which suggested that the initial size of the defect $(2 a)$ was $\sim 0.124 \mathrm{~mm}$.

Since the defect size of $0.124 \mathrm{~mm}$ comes from a single specimen, the value of $0.124 \mathrm{~mm}$ can be treated as an indicative value of the initial defect size on the surface of the specimen. Also, one can expect a reasonable amount of variation in initial defect size if the fractographic measurements were taken on more than one specimen and the defect size from the fractographic image is an estimation only and not a precise measurement. The small crack growth analysis results for the initial defect sizes of $0.1 \mathrm{~mm}$ and $0.170 \mathrm{~mm}$, and its comparison with the test results for the cracks initiating from the surface of the specimens [20] suggests that the analysis predictions are in good agreement with the experimental results, and experimental data are bounded by the crack growth predictions for $0.1-0.17 \mathrm{~mm}$ initial defects sizes. 

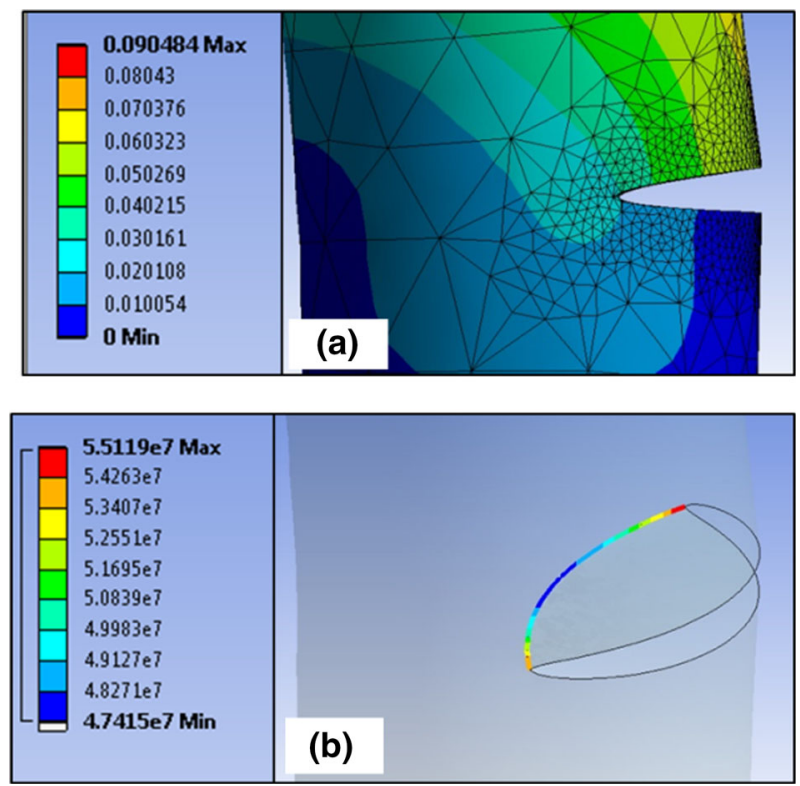

Fig. 11 Contour plots: a total deformation $(\mathrm{mm})$ and $\mathbf{b}$ maximum stress intensity $(\mathrm{Pa} \cdot \sqrt{ } \mathrm{m})$ at final sub-step

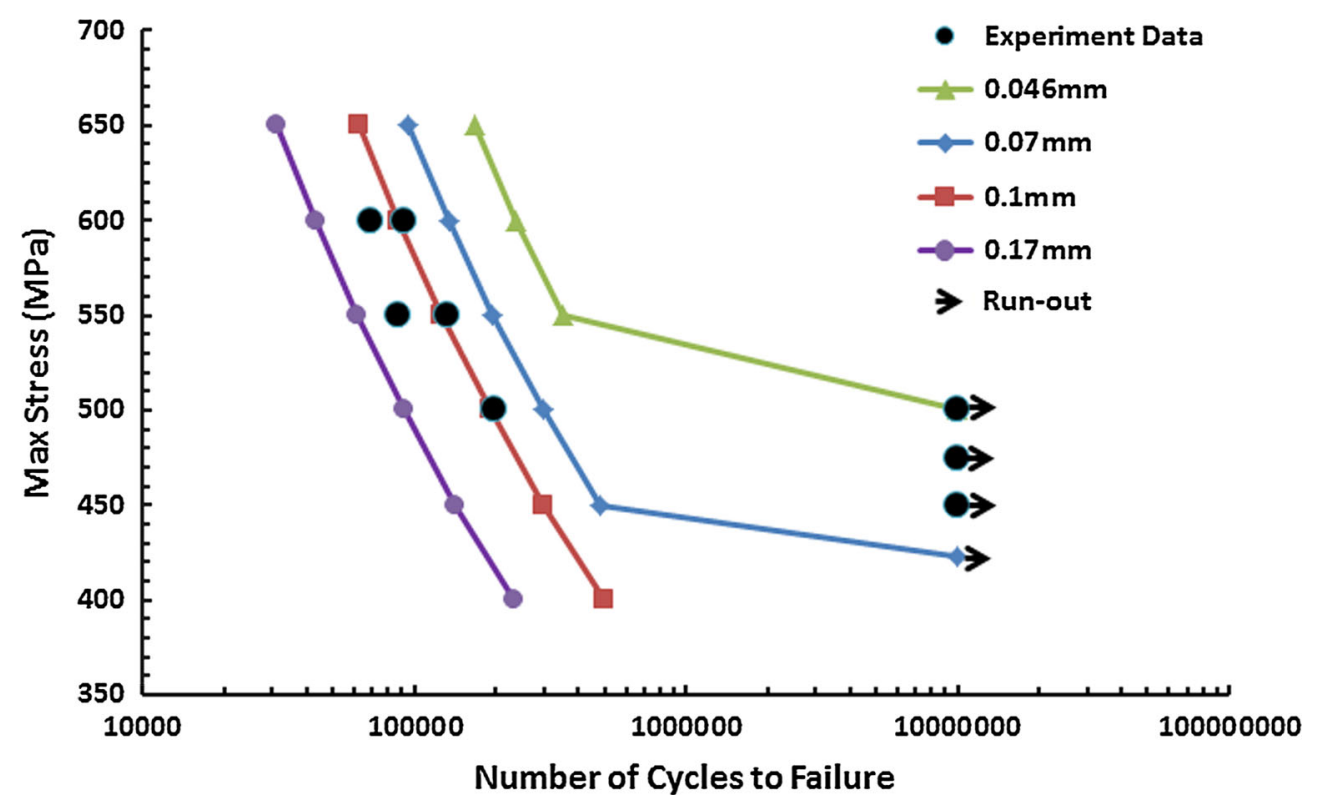

Fig. 12 SMART crack growth analysis predictions versus experimental results-Case A

For the test points indicating run-outs, no images of the fracture surface were provided by Gong et al. [20]; however, since these specimens did not fail, it can be assumed that the initial defects would have been of size less than $0.1 \mathrm{~mm}$. The run-out test points are well bounded by the predicted curves for the defect sizes of $0.046 \mathrm{~mm}$ and $0.07 \mathrm{~mm}$ (Fig. 12).

4.2 Case B: With internal designed defect of cylindrical shape, crack initiating at the surface

As discussed previously in Table 2, for analysis Case B, the small crack growth lifing calculations were performed for initial defect sizes of $0.1 \mathrm{~mm}$ and $0.17 \mathrm{~mm}$ at various stress levels until final fracture. The results were compared against the experimental results in Fig. 14. The predicted lifing curve with an initial defect size 

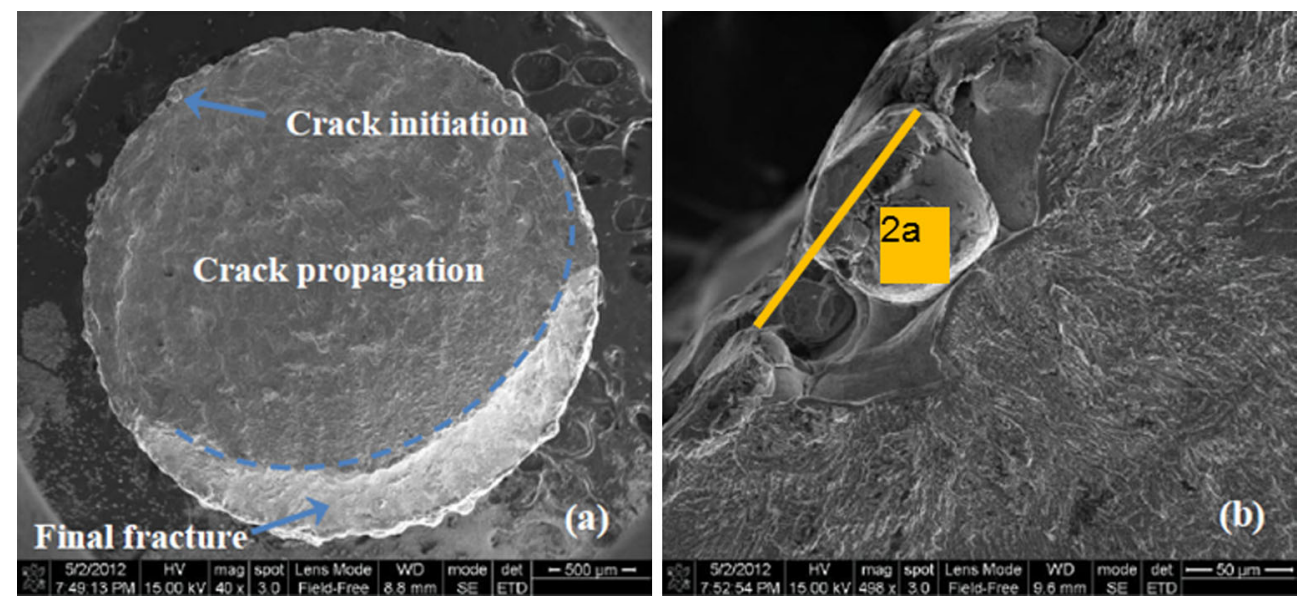

Fig. 13 Fractographic images from experiments-Case A [20]

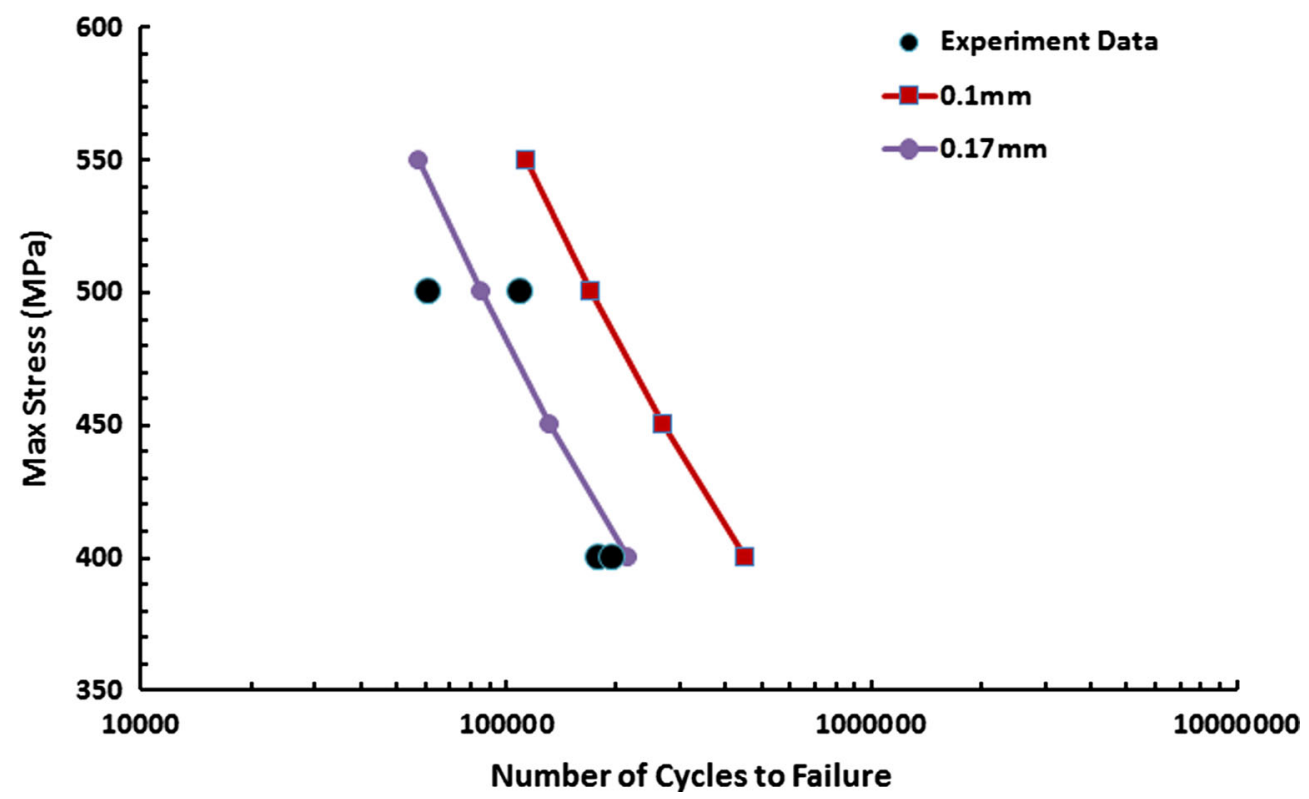

Fig. 14 SMART crack growth analysis predictions versus experimental results-Case B

of $0.17 \mathrm{~mm}$ size follows the test failure points [20]. The analysis for an initial defect size of $0.1 \mathrm{~mm}$ predicted a greater number of cycles until fracture against all four experimentally observed failure points.

Fractographic images were not provided by Gong et al. [20] for the tests corresponding to analysis Case $\mathrm{B}$, so the best estimate of size of a surface defect comes from Fig. 13, which indicates the surface defect of $0.124 \mathrm{~mm}$ size, which is within the bounds of $0.1 \mathrm{~mm}$ and $0.17 \mathrm{~mm}$ for initial defect size, analysed for Case B. Also, the four data points are limited in number and may not represent the whole population of specimens with regard to their surface roughness and size of the initial defect.

Furthermore, in the specimens with an internal designed defect, it is likely that a crack may also simultaneously initiate from the internal designed defect, propagate in the direction opposite to the propagating crack, which was initiated from the surface, and subsequently the two cracks merge into each other. If this happens, then it will result in a reduction in the life to fracture and may provide a better match between the predictions for an initial defect size of $0.1 \mathrm{~mm}$ and the test data; however, at this point, this remains a hypothesis only without any supporting evidence. Also a simulation of simultaneously propagating multiple cracks is not possible within the current ANSYS SMART simulation. 


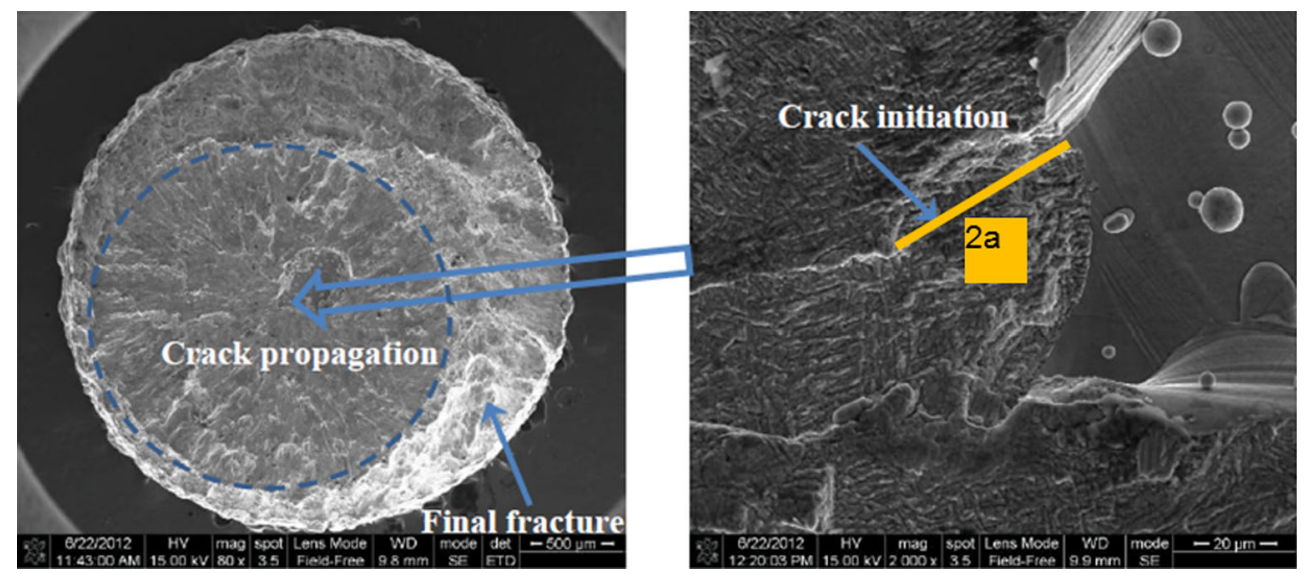

Fig. 15 Fractographic surface of specimens with internal designed defect of cylindrical shape [20] (crack initiated from cylindrical defect)

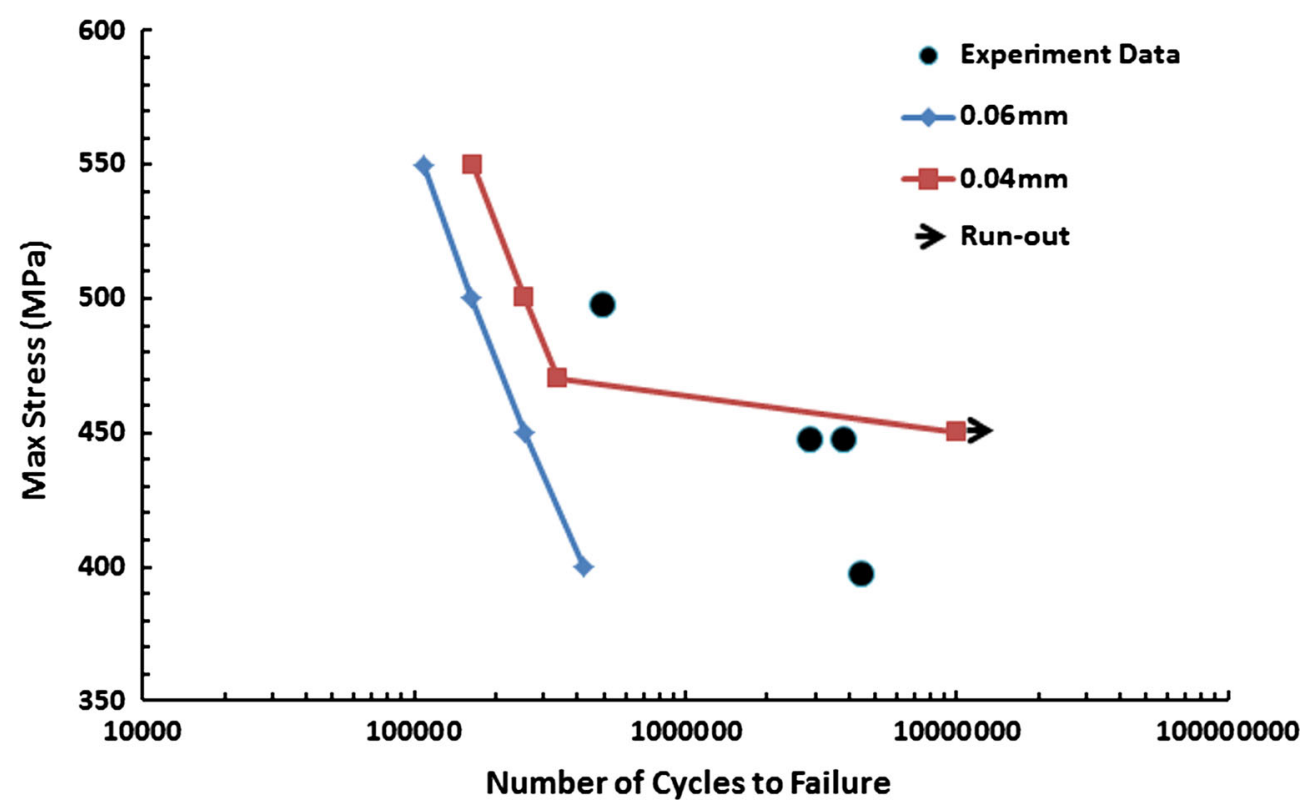

Fig. 16 SMART crack growth analysis predictions versus experimental results-Case C

4.3 Case C: With internal designed defect of cylindrical shape crack initiating at the cylindrical defect

For analysis Case $\mathrm{C}$, crack initiation from the surface of the internal designed defect boundaries was simulated. The stress concentrations around the internal defect and rough surface of the designed defect were assumed to be the cause of crack initiation. It is expected that the designed cylindrical defect would have a detrimental effect on the fatigue life of the specimen because the applied stress will be increased in vicinity of the defect [20]. From the fractographic image of the fracture surface shown in Fig. 15, the initial defect size was approximated as $\sim 0.046 \mathrm{~mm}$.

The small crack growth analysis was performed for the initial defect sizes of $0.04 \mathrm{~mm}$ and $0.06 \mathrm{~mm}$ at stress levels ranging from 400 to $550 \mathrm{MPa}$ until final fracture, and the analysis results were compared against the test results [20] for Case C in Fig. 16. The predicted stress versus number of cycles curve with an initial defect size of $0.04 \mathrm{~mm}$ is in good agreement with the experimental results. The differences between predictions and test results at $400 \mathrm{MPa}$ and $500 \mathrm{MPa}$ could be due to the possible variation in the size of defects in different specimens tested. As it can be seen in Fig. 16, the small crack growth is very sensitive to the initial defect size, where a small change in initial defect size significantly affects the total crack growth life. It is due to the stress concentration effect of internally designed defect. 
For the three cases studied in this paper, the small crack growth model used has shown a reasonably good comparison against the test data. The observed differences between the predictions and experimental results could be attributed to:

- In the short crack model introduced in this study although the factor $U$ changes with increasing $\Delta K$, the value of the threshold stress intensity range for small cracks $\Delta\left(K_{\text {eff }}\right)_{\text {th }}$ used in this study was obtained using the ACR correction method in [27] and used as a constant value in the current study, i.e. does not vary with increasing crack length. Based on the conclusions made by Fomin et al. [22], their proposed small crack growth model takes into account the varying $\Delta\left(K_{\text {eff }}\right)_{\text {th }}$ as a function of crack length ' $2 a$ ' and seems to be more accurate.

- For AM Ti-6AL-4V model, we have not got the sufficient test data to develop the 'cyclic R-curve' and it should be looked into as part of the future research study. This will require a carefully planned extensive and sophisticated test program to study the parameters which affect the small crack growth behaviour of AM Ti-6Al-4V.

- The $p$ value used in Eq. 4 was read across from other similar studies [16,41]. A more accurate $p$ value is required via the HCF tests on AM Ti-6Al-4V material. Fomin et al. [22] have derived the $p$ value by performing a regression analysis on the weld fatigue test data in HCF regime. This is expected to improve the fatigue life predictions in the HCF regime [22].

- The size of initial defect assumed has a direct impact on the small crack growth life predictions and a precise measurement of the defects' size in an AM material remains a challenge. The more advanced scanning techniques, such as X-ray CT scan, and post- processing techniques should be used to characterise the defect sizes which need to be considered to assess the life of the AM part using the predictive models for small crack growth behaviour.

\section{Conclusions}

The small crack growth life prediction method proposed in this paper includes a detailed finite element (FE)based crack growth simulation and lifing calculations using the modified NASGRO equation and small crack growth data.

The small crack growth predictions for the three cases analysed are in reasonably good agreement with the test results [20] for laser AM specimens made of Ti-6Al-4V material. This suggests that the proposed method can be used to predict the crack growth life of AM parts with small defects present.

The difference between the predicted stress versus number of cycle curves and the test data points can be attributed to: (i) lack of a precise measurement of defects' size in the test specimen and (ii) the expected variation in crack growth properties due to AM processes, build parameters and build orientations.

The small defects in an AM part operating in cyclic loading environment can start to propagate immediately as soon as the crack driving force $(\Delta K)$ is big enough at the applied stress levels, ignoring the initiation life.

The correlation between the predictions and test results gives confidence that the modified NASGRO equation can be used to assess the small crack growth life of an AM parts for aerospace applications where the fatigue effects of cyclic loading can be quite significant.

For an accurate simulation and prediction of defect tolerant life of AM parts, the followings important considerations need to be understood and applied in the analysis:

- Size, shape, density and distribution of defects together with AM process and microstructure specific small fatigue crack growth data are the key parameters needed to be understood in detail.

- For the small crack growth lifing calculations, although the long fatigue crack growth data corrected using the ACR approach can be used, the emphasis should also be to build a robust dataset of small crack growth rates for various materials and load conditions. Furthermore, the fatigue and crack growth experimental dataset for AM built materials is required to develop the AM material specific 'cyclic R-curve' to use in the small crack growth model.

- Accuracy of crack growth simulation, i.e. crack geometry, location, boundary condition, loading and material property are other important factors which should be measured and defined accurately in the analysis simulation. A robust training plan and standardisation of analysis method will be required to achieve the consistent and accurate results.

Characterisation of defects in an AM part also needs focus. NDT techniques such as X-ray computed tomography can be used to obtain information on the size, shape, location and distribution of defects. Further, 
the examination methods such as scanning electron microscope (SEM) or electron backscatter diffraction (EBSD) can be used to assess the size, shape and location of defects on the cut plane of the specimen [46].

In the future, studies are needed to be performed to assess the effect of defects in actual AM build parts which experience anisotropic material behaviour and multi-axial state of loading. Many studies have highlighted the need to acquire the small crack growth data to judge the effectiveness of different AM processes with regard to their resistance to small crack growth [16]. Since it is hard to get the small crack growth data [23,28,36,41] due to experimental difficulties, better testing techniques are required to build the material database of small crack growth rate with various materials, loading ratios, AM processes, build parameters, post-build heat treatments and build direction dependent anisotropy. Furthermore, experimental studies are recommended to understand the behaviour of simultaneously propagating small cracks in AM specimens, and at the same time the simulation capability for such cases is required to be developed.

Also, to develop the 'cyclic R-curves' it will require an extensive test and validation program for the AM materials and this must be explored as part of the future research framework to study the short crack growth behaviour in Ti-6Al-4V material and its dependence on build direction, microstructure, temperature, build parameters, environmental effects, etc.

Acknowledgements The authors thank Rolls-Royce plc and the EPSRC for their support under the Prosperity Partnership Grant 'Cornerstone: Mechanical Engineering Science to Enable Aero Propulsion Futures, Grant Ref: EP/R004951/1.'

Open Access This article is licensed under a Creative Commons Attribution 4.0 International License, which permits use, sharing, adaptation, distribution and reproduction in any medium or format, as long as you give appropriate credit to the original author(s) and the source, provide a link to the Creative Commons licence, and indicate if changes were made. The images or other third party material in this article are included in the article's Creative Commons licence, unless indicated otherwise in a credit line to the material. If material is not included in the article's Creative Commons licence and your intended use is not permitted by statutory regulation or exceeds the permitted use, you will need to obtain permission directly from the copyright holder. To view a copy of this licence, visit http://creativecommons.org/licenses/by/4.0/.

\section{References}

1. ASTM F2792-12a (2019) Standard terminology for additive manufacturing technologies, ASTM International. www.astm. org

2. Leuders, S., Thöne, M., Riemer, A., Niendorf, T., Tröster, T., Richard, H.A., Maier, H.J.: On the mechanical behaviour of titanium alloy TiAl6V4 manufactured by selective laser melting: fatigue resistance and crack growth performance. Int. J. Fatigue 48, 300-307 (2013). https://doi.org/10.1016/j.ijfatigue.2012.11.011

3. Kahlin, M., Ansell, H., Moverare, J.J.: Fatigue behaviour of notched additive manufactured Ti6Al4V with as-built surfaces. Int. J. Fatigue 101(1), 51-60 (2017). https://doi.org/10.1016/j.ijfatigue.2017.04.009

4. Molaei, R., Fatemi, A.: Fatigue design with additive manufactured metals: issues to consider and perspective for future research. Procedia Eng. 213, 5-16 (2018). https://doi.org/10.1016/j.proeng.2018.02.002

5. Günther, J., Krewerth, D., Lippmann, T., Leuders, S., Tröster, T., Weidner, A., Biermann, H., Niendorf, T.: Fatigue life of additively manufactured Ti-6Al-4V in the very high cycle fatigue regime. Int. J. Fatigue 94(2), 236-245 (2017). https://doi. org/10.1016/j.ijfatigue.2016.05.018

6. Vayssette, B., Saintier, N., Brugger, C., Elmay, M., Pessard, E.: Surface roughness of Ti-6Al-4V parts obtained by SLM and EBM: effect on the high cycle fatigue life. Procedia Eng. 213, 89-97 (2018). https://doi.org/10.1016/j.proeng.2018.02.010

7. Fatemi, A., Molaei, R., Sharifimehr, S., Phan, N., Shamsaei, N.: Multiaxial fatigue behavior of wrought and additive manufactured Ti-6Al-4V including surface finish effect. Int. J. Fatigue 100(1), 347-366 (2018). https://doi.org/10.1016/j.ijfatigue. 2017.03.044

8. Chastand, V., Tezenas, A., Cadoret, Y., Quaegebeur, P., Maia, W., Charkaluk, E.: Fatigue characterization of Titanium Ti6Al-4V samples produced by additive manufacturing. Procedia Struct. Integr. 2, 3168-3176 (2016). https://doi.org/10.1016/ j.prostr.2016.06.395

9. Cain, V., Thijs, L., Van Humbeeck, J., Van Hooreweder, B., Knutsen, R.: Crack propagation and fracture toughness of Ti6Al4V alloy produced by selective laser melting. Addit. Manuf. 5, 68-76 (2015). https://doi.org/10.1016/j.addma.2014. 12.006

10. Daniewicz, S.R., Shamsaei, N.: An introduction to the fatigue and fracture behavior of additive manufactured parts. Int. J. Fatigue 94(2), 167 (2017). https://doi.org/10.1016/j.ijfatigue.2016.07.007

11. Sterling, A., Shamsaei, N., Torries, B., Thompson, S.M.: Fatigue behaviour of additively manufactured Ti-6Al-4V. Procedia Eng. 133, 576-589 (2015). https://doi.org/10.1016/j.proeng.2015.12.632

12. Gong, H., Rafi, K., Gu, H., Ram, G.D.J., Starr, T., Stucker, B.: Influence of defects on mechanical properties of Ti-6Al-4V components produced by selective laser melting and electron beam melting. Mater. Des. 86, 545-554 (2015). https://doi. org/10.1016/j.matdes.2015.07.147

13. Gong, H., Rafi, K., Gu, H., Starr, T., Stucker, B.: Analysis of defect generation in Ti-6Al-4V parts made using powder bed fusion additive manufacturing processes. Addit. Manuf. 1-4, 87-98 (2014). https://doi.org/10.1016/j.addma.2014.08.002

14. Cao, F., Kumar, P., Koopman, M., Lin, C., Fang, Z.Z., Chandran, K.S.R.: Understanding competing fatigue mechanisms in powder metallurgy Ti-6Al-4V alloy: role of crack initiation and duality of fatigue response. Mater. Sci. Eng. A 630, 139-145 (2015). https://doi.org/10.1016/j.msea.2015.02.028 
15. Zuo, J.H., Wang, Z.G., Han, E.H.: Effect of microstructure on ultra-high cycle fatigue behavior of Ti-6Al-4V. Mater. Sci. Eng. A 473(1-2), 147-152 (2008). https://doi.org/10.1016/j.msea.2007.04.062

16. Jones, R., Michopoulos, J.G., Iliopoulos, A.P., Raman, R.K.S., Phan, N., Nguyen, T.: Representing crack growth in additively manufactured Ti-6Al-4V. Int. J. Fatigue 116, 610-622 (2018). https://doi.org/10.1016/j.ijfatigue.2018.07.019

17. Boyer, R.R.: An overview on the use of titanium in the aerospace industry. Mater. Sci. Eng. A 213(1-2), 103-114 (1996). https://doi.org/10.1016/0921-5093(96)10233-1

18. Sen, I., Gopinath, K., Datta, R., Ramamurty, U.: Fatigue in Ti-6Al-4V-B alloys. Acta Mater. 58(20), 6799-6809 (2010). https://doi.org/10.1016/j.actamat.2010.09.008

19. Sadananda, K., Vasudevan, A.K.: Fatigue crack growth behaviour of titanium alloys. Int. J. Fatigue 27(10-12), 1255-1266 (2005). https://doi.org/10.1016/j.ijfatigue.2005.07.001

20. Gong, H., Khalid, R., Starr, T., Stucker, B.: Effect of defects on fatigue tests of as-built TI-6AL-4V parts fabricated by selective laser melting. In: 23rd Annual International Solid Freeform Fabrication Symposium-An Additive Manufacturing Conference, SFF, pp. 499-506 (2012)

21. Zhan, Z., Li, H., Lam, K.Y.: Development of a novel fatigue damage model with AM effects for life prediction of commonlyused alloys in aerospace. Int. J. Mech. Sci. 155, 110-124 (2019). https://doi.org/10.1016/j.ijmecsci.2019.02.032

22. Fomin, F., Horstmann, M., Huber, N., Kashae, N.: Probabilistic fatigue-life assessment model for laser-welded Ti-6Al-4V butt joints in the high-cycle fatigue regime. Int. J. Fatigue 116, 22-35 (2018). https://doi.org/10.1016/j.ijfatigue.2018.06.012

23. Zerbst, U., Vormwald, M., Pippan, R., Gänser, H.P., Sarrazin-Baudoux, C., Madia, M.: About the fatigue crack propagation threshold of metals as a design criterion-a review. Eng. Fract. Mech. 153, 190-243 (2016). https://doi.org/10.1016/j. engfracmech.2015.12.002

24. Zerbst, U., Madia, M., Vormwald, M., Beier, HTh: Fatigue strength and fracture mechanics—a general perspective. Eng. Fract. Mech. 198, 2-23 (2018). https://doi.org/10.1016/j.engfracmech.2017.04.030

25. Kitagawa, H., Takahashi, S.: Applicability of fracture mechanics to very small cracks or the cracks in the early stage. Proceedings of the 2nd International Conference on Mechanical Behaviour of Materials, Boston, MA, pp. 627-631 (1976)

26. Murakami, Y.: Metal Fatigue: Effects of Small Defects and Nonmetallic Inclusions. Elsevier, Oxford (2002)

27. Zhai, Y., Lados, D.A., Brown, E.J., Vigilante, G.N.: Fatigue crack growth behaviour and microstructural mechanisms in Ti-6Al-4V manufactured by laser engineered net shaping. Int. J. Fatigue 93(1), 51-63 (2016). https://doi.org/10.1016/j. ijfatigue.2016.08.009

28. Gavras, A.G., Lados, D.A., Donald, J.K.: A unified method of design for fatigue crack growth resistance in structural materials. Int. J. Fatigue 47, 58-70 (2013). https://doi.org/10.1016/j.ijfatigue.2012.07.009

29. Suresh, S., Ritchie, R.O.: Propagation of short fatigue cracks. Int. Met. Rev. 29(1), 445-475 (1984). https://doi.org/10.1179/ imtr.1984.29.1.445

30. Pippan, R., Hohenwarter, A.: Fatigue crack closure: a review of the physical phenomena. Fatigue Fract. Eng. Mater. Struct. 40(4), 471-495 (2017). https://doi.org/10.1111/ffe.12578

31. Cui, W.: A State-of-the art review on fatigue life prediction methods for metal structures. J. Mar. Sci. Technol. 7(1), 43-56 (2002). https://doi.org/10.1007/s007730200012

32. Wanhill, R.J.H.: Chapter two - fatigue requirements for aircraft structures. In: Jones, R., Baker, A., Matthews, N., Champagne, V. (eds.) Aircraft Sustainment and Repair, pp. 17-40. Butterworth-Heinemann, Oxford (2018). https://doi.org/10.1016/B9780-08-100540-8.00002-9

33. Vasudevan, A.K., Sadananda, K., Iyyer, N.: Fatigue damage analysis: issues and challenges. Int. J. Fatigue 82(2), 120-133 (2016). https://doi.org/10.1016/j.ijfatigue.2015.08.026

34. Vasudevan, A.K., Sadananda, K., Glinka, G.: Critical parameters for fatigue damage. Int. J. Fatigue 23(1), 39-53 (2001). https://doi.org/10.1016/S0142-1123(01)00171-2

35. Elber, W.: The significance of fatigue crack closure. In: Rosenfeld, M. (ed.) Damage Tolerance in Aircraft Structures, ASTM STP 486, pp. 230-242. American Society for Testing and Materials, West Conshohocken (1971). https://doi.org/10.1520/ STP26680S

36. Donald, J.K., Bray, G.H., Bush, R.W.: An evaluation of the adjusted compliance ratio technique for determining the effective stress intensity factor. In: Panontin, T.L., Sheppard, S.D. (eds.) Fatigue and Fracture Mechanics: Twenty-Ninth Volume, ASTM STP 1332. American Society for Testing and Materials, West Conshohocken (1999)

37. Sinha, V., Mercer, C., Soboyejo, W.O.: An investigation of short and long fatigue crack growth behavior of Ti-6Al-4V. Mater. Sci. Eng. A 287(1), 30-42 (2000). https://doi.org/10.1016/S0921-5093(00)00817-0

38. Gaëlle, C., Christine, S.B., Laurie, L., Zeline, H.: Near-threshold fatigue propagation of physically short and long cracks in titanium alloy. Procedia Struct. Integr. 2, 950-957 (2016). https://doi.org/10.1016/j.prostr.2016.06.122

39. Lawson, L., Chen, E.Y., Meshii, M.: Near-threshold fatigue: a review. Int. J. Fatigue 21(1), S15-S34 (1999). https://doi.org/ 10.1016/S0142-1123(99)00053-5

40. Zhang, W., Wang, Q., Li, X., He, J.: A simple fatigue life prediction algorithm using the modified NASGRO equation. Math. Probl. Eng. (2016). https://doi.org/10.1155/2016/4298507

41. Jones, R., Peng, D., McMillan, A.J.: Chapter five—crack growth from naturally occurring material discontinuities. In: Jones, R., Baker, A., Matthews, N., Champagne, V. (eds.) Aircraft Sustainment and Repair, pp. 129-189. Butterworth-Heinemann, Oxford (2018). https://doi.org/10.1016/B978-0-08-100540-8.00005-4

42. Ansys-SMART Fracture white paper (2018). https://www.ansys.com/-/media/Ansys/corporate/resourcelibrary/whitepaper/ smart-fracture.pdf

43. ASTM F1472-14 Standard specification for wrought Titanium-6Aluminum-4Vanadium alloy for surgical implant applications (UNS R56400), ASTM International (2019). www.astm.org

44. ASTM E647-15 Standard test method for measurement of fatigue crack growth rates, ASTM International (2015). www. astm.org

45. Lewandowski, J.J., Seifi, M.: Metal additive manufacturing: a review of mechanical properties. Annu. Rev. Mater. Res. 46(1), 151-186 (2016). https://doi.org/10.1146/annurev-matsci-070115-032024 
46. Fatemi, A., Molaei, R., Simsiriwong, J., Sanaei, N., Pegues, J., Torries, B., Phan, N., Shamsaei, N.: Fatigue behaviour of additive manufactured materials: an overview of some recent experimental studies on Ti-6Al-4V considering various processing and loading direction effects. Fatigue Fract. Eng. Mater. Struct. 42(5), 991-1009 (2019). https://doi.org/10.1111/ ffe. 13000

Publisher's Note Springer Nature remains neutral with regard to jurisdictional claims in published maps and institutional affiliations. 